\title{
Granularity Effects in Tense Translation
}

\author{
Michael Schiehlen* \\ Institute for Computational Linguistics, University of Stuttgart, \\ Azenbergstr. 12, 70174 Stuttgart \\ mike@adler .ims . uni-stuttgart .de
}

\section{Introduction}

One of the daunting problems in machine translation (MT) is the mapping of tense. The paper singles out the problem of translating German present tense into English. This problem scems particularly instructive as its solution requires calculation of aspect as well as determination of the temporal location of events with respect to the time of speech. We present a disambiguation algorithm which makes use of granularity calculations to establish the scopal order of temporal adverbial phrases. The described algorithm has been implemented and is running in the Verbmobil system.

The paper is organized as follows. In sections 2 through 4 we present the problem and discuss the linguistic factors involved, always kceping an eye on their exploitation for disambiguation. Sections 5 and 6 are devoted to an abstract definition of temporal granularity and a discussion of granularity effects on scope resolution. In section 7 the actual disambiguation algorithm is presented, while section 8 describes its performance on the Verbmobil test data. A summary closes the paper.

\section{Present or Future?}

In contrast to English, the German present tense is commonly used to describe both present and future happenings. One task in translation from German to English is therefore the disambiguation of German present tense to present time or future time.

(1) present tense $\rightarrow$ future time $\rightarrow$ present time

\footnotetext{
* This work was funded by the German Federal Ministry of Education, Science, Research and Technology (BMBF) in the framework of the Verbmobil Project under Grant 01 IV 101 U. Many thanks are due to Prof. H. Kamp and K. Eberle. All errors are my own.
}

\subsection{Temporal Orientation}

A promincnt factor involved in the choice between present and future time (Butt, 1995) is the temporal orientation of the time adverbials that modify the tensed verb.

Only a limited set of time adverbials can refer to present time. Indeed, the set is so small that it can be enumerated. The adverbials can be further subclassified according to other times they may refer to.

- only present (now, at the moment)

- also past (just, German eben)

- any time (today, this wock, in the meantime, for two weeks)

All other time adverbials are incompatible with present time.

(2) * On 19th November 2000, I sleep late.

- Some adverbials only refer to past time (e.g. yesterday, last woek, formerly, recently, two days ago).

(3) * I will be here yesterday.

- Others can only be used with future time (tomorrow, next week, soon, in four days).

\subsection{Verbs Immune to Temporal Orientation Effects}

In some cases the temporal orientation of adverbials sounds a false alarm: Even though an adverbial requiring non-present syntactically modifies the tensed verb, German present tense is translated as present (see examples (4) from the British National Corpus). The effect comes about bccause semantically the adverbial modifies not the verb's eventuality but one of the verb's objects. 
(4) a. Tomorrow I am already planning a golf trij) with tho boss. (Verbmobil corpus)

b. And we wish him the very best of luck tomorrow in Birmingham.

(British National Corpus, I3NC)

c. Another storm from SE .. is expected here tomorrow.

$(\mathrm{BNC})$

The decisive factor seems to be the verb sense involved. Thus, for disambiguation a list of such "immune" verb senses must be compiled. Such verlos can be modified by adverbials recuiring present and adverbials requiring non-present at the same time.

(5) am Montag haben wir jotzt noch ctwas Zcit on Monday have wo now still some time but now we still have some time on Monday.

\subsection{Temporal Orientation and Scope}

Only the temporal orientation of wide-scope adverbials is relevant for tense clisambiguation (Butt, 1995). Frequency adverbials intercept the disambiguating offect (see (6)). It is therefore important to evaluate only those adverbials that outscope the frequency adverbial with widest scope.

(6) a. John will be here on Monday.

b. John is here on Monday every week.

c. John will bo here in April every woek.

\section{Simple or Progressive?}

A distinctive feature of the English tense system that is missing in German is the differentiation between simple and progressive aspect. We focus here on the usage of aspect in present time.

(7) present time $\rightarrow$ simple present $\rightarrow$ present progressive

\subsection{Linguistic Factors}

The factors involved have becn thoroughly studied and classified in the linguistic literature (Grcenbaum and Quirk, 1990). So we confine ourselves to a short review here.

State Present. Stative verb senses get simple aspect.

(8) a. * We are having a house on Oxford Street.

b. We are having dinner.
Habitual Present. A habit is a set of events of the same type. In semantic terms, a habit arises from quantification over events. If the events extend inderinitely into the pasti and future, the liabit is conceived as permanent and simple aspect is used; if the events occur over a limited period of time, the habit is conceived as temporary and progressive aspect is appropriate. A frequency adverbial can be used to specify the (relative) number of occurrences of the event. General facts can be viewed as a special type of a habit. They are always expressed in simple aspect (sec (9)).

(9) Because water boils at $100^{\circ} \mathrm{C}$, water is boiling at $100^{\circ} \mathrm{C}$ in the pot.

Instantaneous Present. Dynamic verb senses that refor to a single event with littlo or no duration occurring at the specch time are expressed with simple aspect. This type of present is used in commentarios (10a), solf-commentaries (10b) and with performative verbs (10c) referring to speech acts.

(10) a. Joo scores a goal.

b. I cnclose an application form.

c. For permission to publish this paper, the authors thank the Department of Feonomic Development.

Durational Present. Dynamic verb senses denoting an incomplete event with duration get progressive aspect.

(11) a. We are looking at March sixtecnth.

(Verbmobil corpus)

b. 'This is looking interesting.

(Verbmobil corpus)

\subsection{Disambiguation}

State Present. Disambiguation requires definition and classification of all relevant verb senses according to stativity. When in a first approximation only the most frequent verb scuse of each verb are considered, a list of stative verbs can be extracted from a corpus.

Habitual Present. The presence of a frequency adverbial points to a reading of Habitual present. Since every event can be construed as a general fact, general facts are very difficult to identify and will bo disregarded. 
Instantaneous Present. For disambiguation achievement verbs used in self-commentaries and performative verbs noed to be listed.

Durational Present. Present events are usually regarded as having duration, so progressive is the default aspect for dynamic verb senses in the present.

\section{Perfect or Not?}

In a special case, German present tense can bo rendered as English present perfect: In English, perfect is used to describe periods that begin in the past and lead up to the present; German uses a non-perfective tense in this situation.

(12) Wir leben schon fünf Jahre in Amsterdam. We live already five years in Amsterdam. We have lived in Amsterdam for five years.

Whenever a period is described that begins before and still holds at speech time, a limitative time adverbial ${ }^{1}$ is used. (This term is due to Bras (1990).) This peculiarity makes disambiguation very easy.

(13) a. Er ist erst zwci Wochen hier. He is onlyt two weoks hore. He has only been here for two weeks.

b. Er ist nur zwei Wochen hicr. He is only two weeks here. He is here for only two weeks.

\section{Definition of Granularity}

For our purposes wo model the time axis as the set of rational ${ }^{2}$ numbers $\mathbb{Q}$. An interval is then a pair of rational numbers $\langle s, c\rangle$, such that $s<e$. The duration of an interval is the distance between start and end of the interval $(\operatorname{dur}(\langle s, c\rangle)=e-s)$. On the interval structure we define the relations of inclusion (14a) and overlap (14b).

$$
\begin{aligned}
\text { (14) a. }\left\langle s_{1}, e_{1}\right\rangle \subseteq\left\langle s_{2}, e_{2}\right\rangle \leftrightarrow s_{2} \leq s_{1} \wedge e_{1} \leq e_{2} \\
\text { b. }\left\langle s_{1}, e_{1}\right\rangle \bigcirc\left\langle s_{2}, e_{2}\right\rangle \leftrightarrow s_{1} \leq e_{2} \wedge s_{2} \leq e_{1}
\end{aligned}
$$

\footnotetext{
${ }^{1}$ Limitative adverbials go with the prepositions since and for plus temporal measure nouns in English; in German they occur with the preposition seit and as duration adverbials modified by schon and erst.

${ }^{2}$ Although natural numbers could have been used too, rational numbers are convenient, since they allow free choice of the unit.
}

\subsection{Temporal nouns}

A temporal noun denotes a set of intervals. We define the granularity of a temporal noun formally as a pair of numbers specifying the minimal and maximal duration of its intervals (c.g. $\operatorname{gran}($ day $)=\langle 1,1\rangle, \operatorname{gran}($ conference $)=\langle 1,28\rangle$, gran(seminar) $=\langle 0.00138889,334.812\rangle$ if the unit is a day). The following relation is used to compare granularity values.

$$
\text { (15) } \begin{aligned}
\left\langle d u r_{1}^{1}, d u r_{2}^{1}\right\rangle & >\left\langle d u r_{1}^{2}, d u r_{2}^{2}\right\rangle \leftrightarrow \\
\left\langle d u r_{1}^{1}, d u r_{2}^{1}\right\rangle & \neq\left\langle d u r_{1}^{2}, d u r_{2}^{2}\right\rangle \wedge d u r_{1}^{1} \geq d u r_{2}^{2}
\end{aligned}
$$

If $n_{1}$ has coarser granularity than $n_{2}$, then an interval of $n_{1}$ cannot be included in an interval of $n_{2}$.

$$
\text { (16) } \begin{aligned}
& \forall n_{1}, n_{2}:\left(\operatorname{gran}\left(n_{1}\right)>\operatorname{gran}\left(n_{2}\right) \rightarrow\right. \\
&\left.\forall i_{1} \in n_{1}, i_{2} \in n_{2}: i_{1} \not i_{2}\right)
\end{aligned}
$$

Consider the following definition.

(17) A temporal noun $n$ has the property of disjointness iff $\forall i_{1}, i_{2} \in n: \neg i_{1} \mathrm{O} i_{2}$

Every calendar measure noun defines a partition on the time axis and has therefore the property of disjointness (e.g. hour, day, weck, etcrnity). Nouns functionally dependent on calcndar measure nouns inherit the property (c.g. Monday, Christmas, holiday, 6:45, ...). Event and state nouns have the disjointness property, if the described intervals functionally depend on one of the participants and the participant is definite. Thus, example (18) is deviant.

(18) * Tomorrow at 6:30 Jones will give a talk at every conference.

If $n_{1}$ has fincr granularity than a noun $n_{2}$ which has the property of disjointness, then every interval in $n_{1}$ overlaps with at most one interval in $n_{2}$ (we disregard the case where $i_{1}$ joins two intervals in $n_{2}$ ).

$$
\text { (19) } \forall i_{1} \in n_{1}:\left|\left\{i_{2}: i_{2} \in n_{2} \wedge i_{1} O i_{2}\right\}\right| \leq 1
$$

\subsection{Functions on Granularity}

Relational Nouns. Among the temporal relational nouns we distinguish nouns describing periods of definite length (c.g. quarter, third, half) from those that refer to periods of indefinite length (e.g. beginning, middle, ond). In granularity calculation, relational nouns contribute a factor. With relational nouns referring 
to periods of indefinite length wo sot the factor tio $\frac{1}{2}$.

Temporal prepositions. Temporal prepositions are malpjed to interval rolations.

1. Some prepositions do not alter gramularity (c.g. temporal location on, in, att, duration during, througliout, for).

2. Somo prepositions describe an open-ended interval (e.g. bofore, after, from-on, nutil).

3. Somo prepositions require a detailed determination of temporal reference if they are to yich gramularity predictions (o.g. since, betwoeni).

T'o calculate grambalaty with the latter two classes, we take the gramularity of the prepositions' NP arguments as a guidoline. 'Tho houristic assumption is that if a time adverbial is to designate a long poriod more dotail is given in the NP argument. 'I'hus, the relevant temporal prepositions map the nown gramularity to the noxt higher level on a cortiain scale (day month -.. yoa. - eternity).

(20) before 6:30 (s day)

before Monday ( $\leq$ month or you.)

before Monday, 1st of October ( $\leq$ your $)$

before Monday, 1st of octolon 1998

(infinite)

Determiners. Two classes of determinors can be distingubshed: specific: (dolinite or indefinite) and quantificational (Kamp) and Royle, 1993). Specific determiners do not change gramularity. Quantifiers, however, extend granularity if it is clear that every interval demoted by a temporal noun occurs only once within a certain period.

\section{(21) every Mondlay (wodk)}

every begimning of a conforence

(conference)

every bimonthly mecting (two monthis)

BU'I: every quarter of a year (three months, not; year:)

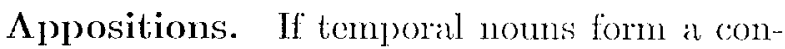
stituent (o.g. yosterday aftomoon), tho granularity of the hoad noun is chosen (typically this is the finer granularity). Sinco intervals aro msually described on somec and target side, granularity information of both source and liarget temporal nonns can be exploited to achicve higher precision (c.g. Vormittag - morning).

\section{Scope Resolution}

For tense disambiguation scope resolution of time adverhials cas be crucial (cf. section 2.3).

\subsection{Functional Concepts}

Functional concepts restrict the possibilities of scope resolution (Alshawi, 1992).

A quantificr $Q(x, R, S)$ is itcrative iff it requires that conceptual knowledge allows for at loast two objects in the intersection of its restriction $R$ and nuclear scope $S(\mid\{x: R(x) \wedge$ $S(x)\} \mid>1)$. Examples for itcrative quantifiors are every, most, several and tho distributive rading of plural.

A concept $C$ is functional on domain $D$ and ramge $R$ ifl $\vee x: D(x) \rightarrow|\{y: W(y) \wedge C(x, y)\}| \leq$ 1 (c.g. every human has exactly one father).

It can be shown that if an iterative quantifier quantifies over the sange of a functional concept, it must outscope tho domain quantifier (e.g. ovory father ontiscopes a student in overy father of a student) (Moran and Porcira, 1992).

temporal overlap is a functional concept if the domain interval has fincr granularity than the range interval (see (19)). Hence, if two time adverbials $n_{1}$ (on Monday in (22)) and $n_{2}$ (overy weok in (22)) nodify the same event, $n_{1}$ has finer granularity than $n_{2}$, and $n_{2}$ is itcratively quantificd, then $n_{2}$ musti ontscope $n_{1}$.

(22) John visited .Jane every week on Monday.

\subsection{Temporal Quantification}

'lemporal quantilication has a curious propenty. Prepositional phrases are generally treated as intersective modifiers to the hoad instance ( $\mathrm{Al}$ shawi, 1992). If we analyse sentence (23a) in this voin, wo get (23b) as logical representation: The described events are situated in May and in cvery woek.

(23) a. In May Jolnn visited Jane cvery woek.

b. $\exists m: \operatorname{May}(m) \wedge \forall u): \operatorname{wock}(w) \rightarrow \exists e:$ visit (e, John, Jane) $\wedge e \subseteq m \wedge e \subseteq w$

On closer inspection we see that the representiation is contradictory. 'Take an arbitrary woek, say in April. Then the formula asserts that there is a visit in this week (i.e. in April) and 
in May, which is inconsistent. Thus, the formula should not quantify over weeks in general but over weeks in May: An inclusion restriction to the widc-scope adverbial is necded in the narrow-scope adverbial (Kamp and Reyle, 1993)

(24) $\exists m: \operatorname{May}(m) \wedge \forall w: \operatorname{week}(w) \wedge w \subseteq m \rightarrow$ $\exists e: \operatorname{visit}(e, J o h n$, Jane $) \wedge e \subseteq m \wedge e \subseteq w$

Since temporal quantification requires that a narrow-scope iterative adverbial be included in the wide-scope adverbial, configurations are excluded where by conceptual knowledge the narrow-scope adverbial $a_{1}$ cannot be included in the wide-scope adverbial $a_{2}$. By theorem (16) this is the case if $a_{1}$ has coarser gramularity than $a_{2}$.

\subsection{Granularity and Scope}

We have now secn two motivations for the principle (25).

(25) If $n_{1}$ has finer granularity than $n_{2}$ and $n_{2}$ is iteratively quantified, $n_{1}$ cannot have scope over $n_{2}$.

Let us now consider the following principle:

(26) If $n_{1}$ has finer granularity than $n_{2}$ and $n_{\mathrm{J}}$ is iteratively quantified, $n_{1}$ camnot have scope over $n_{2}$.

We are not in a position to formally explain the principle. It holds for at least all nouns with the disjointmess property. Although in example (27a) the $\forall \exists$ reading would make perfect sense (Jones is always on holiday), it is excluded. In contrast, example (27b) allows this reading (Jones shuttles between conference sites). The principle is not restricted to temporal granularity: In (27c) the $\forall \exists$ reading is cxcluded, too.

(27) a. Every Monday, Jones was here in a month in which he was on holiday.

b. Every afternoon, Jones gave a talk at a conference.

c. On every page, I found something interesting in a paper I read.

Taken together, the two principles assert that the granularity ranking determines the scope order. In the disambiguation algorithm presented in section 7 we are mainly interested in the position of the highest (iterative) quantificr. So if every pair of time adverbials can be compared in terms of granularity, we have a procedure to compute this position. Comparison of granularity (1.5) is not defined if the granularity values overlap or are equal. Equal gramularity is only possible with specific time adverbials.

(28) * John came from every Wednesday to every weckend

Other heuristics will have to come into play in case of overlapping granularity (see section 8 for further discussion).

\subsection{Deictic Adverbials}

Another factor for determining scope order is deixis. Some adverbials are connected in their interpretation to the time of speech (now, at the moment, next week, last week). Since time of speech is deictic (it depends on the context of utterance), hence definite, every function on it will also be definitc. Deictic adverbials always get wide-scope position.

Sentences in which deixis conflicts with granularity are deviant.

(29) * Next month, I will be hore every yeas.

\section{The Disambiguation Algorithm}

In the implementation, an underspecified semantic representation formalism is used to cncode the source analysis and the transfer result for the target (the Verbmobil Interface Term (VIT) formalism (Bos et al., 1998), which is based on the theory of Underspecified Discourse Representation Structures (Reyle, 1995)). The disambiguation heuristics of the system completely rely on local context. The most important features in local context are source tense, the predicate names of the tensed verb in source and target, and the time adverbials modifying the verb in source and target (Schichlen, 1998). In a first step, the source and target representations are converted into an abstract representation, using the VIT transfer formalism (Dorna and Emele, 1996). All information irrelevant to tense resolution is removed. Since no fullfledged tense logic is implemented, information about temporal reference is discarded as well. Temporal adverbs are decomposed into prepositional phrases (e.g. yesterday $\rightarrow$ on a past 
day). In particular the following features are extracted:

(30) a. multiple classification of verb senses

- stative or dynamic (for English only, cf. section 3.2)

- potentially performative/selfcommentary or not (for English only, cf. section 3.2)

- "immune" or not (cf. section 2.2)

b. temporal relation expressed by prepositions

c. temporal orientation of prepositions (on Monday), adjectives (tho previous Monday) and determiners (this Monday) (cf. section 2.1)

d. granularity of nouns and adverbs (e.g. German ganztägig (whole-day))

c. classification of detcrminers (quantificational/specific/ambiguous)

f. classification of adverbs (frequency adverb or not)

We now give an outline of the disambiguation algorithm for translating Gorman present. It is clear that the algorithm is heuristic in many aspects, but in the absence of context and detailed discourse analysis it does not seem possible to do much better.

1. For every tensed verb, determine all time adverbials modifying it and collect them in the set $T A$.

2. Order the time adverbials in $T A$ according to scope (cf. section 6).

3. Let ST'A be the set of all specific time adverbials in $T^{\prime} A$ (i.c. adverbials denoting a specific interval) not in the scope of a quantificational adverbial or frequency adverb (cf. section 2.3).

4. Perfect or Not? (cf. scetion 4)

If one of the time adverbials in $S T A$ is connected to the tensed verb over a limitative relation, choose perfect; else choose nonperfective tense.

5. Present or Future? (cf. section 2) Choose present if the verb is "immune" to temporal orientation (cf. section 2.2). Else unify the temporal orientation contributed by the time adverbials in $S T A$. In case the result excludes present time, choose future; else choose present (cf. section 2.1).

6. Simple or Progressive Aspect? (cf. section 3)

(a) If the tensed verb has a stative sense, choose simple (State Present).

(b) If the tensed verb is used in a selfcommentary or performatively, choose simple (Instantaneous Present).

(c) If there is an adverbial in $S T A$, choose progressive (Temporary Habit and Durational Present).

(d) If there is a quantificational adverbial or frequency adverb in $T A$, choose simple (Permanent Habit).

(c) Else choose progressive (Durational Present).

\section{Results}

We tested the system on a data base of 13,625 pairs of German VIT's with their English translations, containing 12,036 tensed verbs. All the data were in the appointment scheduling domain which is investigated in Verbmobil. They were transliterated and syntactically annotated by hand. Translation was performed by the Verbmobil transfer component (Dorna and Emcle, 1996). 2,758 tonsed verlos were modified by time adverbials, 1,373 of these verbs were modified by time adverbials with known granullarity.

The algorithm made the following choices for these data. The second column shows the total number of tensed verbs, the third column only counts those modified by time adverbials with granularity.

\begin{tabular}{|l|r|r|}
\hline Perfect & 0 & 0 \\
Future & 729 & 729 \\
State or Instantancous Present & 8,782 & 516 \\
Permancnt Habit & 29 & 29 \\
Dynamic Present & 2,496 & 99 \\
\hline
\end{tabular}

The described algorithm only inspects linguistic factors. Domain-specific information could potentially improve results. In the Verbmobil domain e.g. several event types do not happen in 
the present but only in the future (travel, meet, eat, ...).

In $93.6 \%$ of the cases a specific wide-scope time adverbial could be determined with gramularity constraints. In $4.7 \%$ of the cases several time adverbials of equal granularity had wide scope. A good dcal of these cases were alignment crrors with the translations (c.g. äbermorgen the day after tomorrow). Other cases were due to the lack of a treatment for coordination (e.g. on Monday and on Thursday or from June to August). Some cases were genuine double descriptions of days:

(31) a. Is it possible for you tomorrow on the second?

b. I would have time on Wednesday on Wednesday the third of May.

In $1.7 \%$ of the cases the wide-scope adverbial could not be determined because some adverbials had overlapping granularity values. Here the main culprit was the unspecified adverb when (see (32a)). Other cases were due to incorrect preposition attachment (sce (32b)).

(32) a. When shall we meet on Monday? Next week $/ 6: 30$.

b. Would you be available in the time period until Jume?

\section{Summary}

The paper has presented a disambiguation algorithm for translation of German present into English. After a discussion of the factors involved, particular emphasis was placed on an account of scope resolution among time adverbials. It has been shown that granularity calculations go a long way towards the goal of full scope resolution. The cross-connections between granularity and scope have been analysed in detail, and some motivation for these connections has been given.

One area of future work is to apply the model to larger corpora and extend it to cover the full set of tenses. If translations can be aligned with the training data, it would be interesting to investigate the extent to which the model can be used to extract (parts of) the pertinent granularity information on temporal nouns from the corpus (Schichlen, 1998). For example, the occurrence of a configuration like (33) could be interpreted as evidence for NOUN having coarser granularity than weck.

(33) FUTURE-EVENT every week in NOUN

\section{References}

Hiyan Alshawi. 1992. The Core Language Engine. MIT Press, Cambridge, MA, USA.

Johan Bos, Bianka Buschbeck-Wolf, Michael Dorna, and C.J. Rupp. 1998. Managing information at linguistic interfaces. In Proceedings of the 17th International Conference on Computational Linguistics (COLING '98), Montrcal, Canada.

Myriam Bras. 1990. Calcul des Structures Temporelles du Discours. Ph.D. thesis, Université Paul Sabatier de Toulouse.

Miriam Butt. 1995. Transfor I: Tense and Aspect. Verbmobil Report 55, SfS, Universität Tübingen, Germany, January.

Michacl Dorna and Martin C. Emelc. 1996. Semantic-Based Transfer. In Proceedings of the 16th. International Conference on Computational Linguistics (COLING '96), Copenhagen, Denmark.

Sidney Greenbaum and Randolph. Quirk. 1990. A Student's Grammar of the English Language. Longman, Harlow, England.

Hans Kamp and Uwe Reyle. 1993. From Discourse to Logic: An Introduction to Modeltheoretic Semantics of Natural Language. KJuwer Academic l'ublishers, Dordrecht, Holland.

Douglas B. Moran and Fernando C.N. Pereira. 1992. Quantifier Scoping. In Hiyan Alshawi, editor, The Core Language Engine, chapter 8. MIT Press, Cambridge, MA, USA.

Uwe Reyle. 1995. On Reasoning with Ambiguitics. In Proceedings of the 7th Conference of the European Chapter of the Association for Computational Linguistics (EACL'95), pages 18, Dublin, Ireland.

Michael Schichlon. 1998. Learning Tense Translation from Bilingual Corpora. In Proceedings of the 17th International Conference on Computational Linguistics (COLING '98), Montrcal, Canada. 